\title{
Feeding in a heterogeneous environment: spatial dynamics in summer foraging Barents Sea cod
}

\author{
Edda Johannesen ${ }^{1, *}$, Ulf Lindstrøm ${ }^{2}$, Kathrine Michalsen ${ }^{1}$, Mette Skern-Mauritzen ${ }^{1}$, \\ Per Fauchald ${ }^{3}$, Bjarte Bogstad ${ }^{1}$, Andrey Dolgov ${ }^{4}$ \\ ${ }^{1}$ Institute of Marine Research, 5817 Bergen, Norway \\ ${ }^{2}$ Institute of Marine Research, 9294 Tromsø, Norway \\ ${ }^{3}$ Norwegian Institute for Nature Research, 9296 Tromsø, Norway \\ ${ }^{4}$ Polar Research Institute of Marine Fisheries and Oceanography, Murmansk 183038, Russia
}

\begin{abstract}
Cod Gadus morhua are important predators in many ecosystems in the North Atlantic, but their ecological importance has diminished in many areas due to stock size reductions. In contrast, the Barents Sea cod stock is currently the world's largest and at a high level. The goal of our study was to elucidate spatial aspects of cod-prey interactions in the Barents Sea during recent warm years (2004 to 2009). We used data on cod and prey distributions and cod diet collected during the Barents Sea ecosystem survey. Local prey use, feeding success, spatial displacement and spatial overlap between cod ( $>2 \mathrm{yr}$ ) and prey (capelin, herring, polar cod, shrimp and macrozooplankton) were analysed. While prey species were found in spatially segregated habitats, cod were widely distributed, except the deepest parts of the Barents Sea where shrimps prevailed. Local diet reflected local prey availability. Cod abundance was higher in areas occupied by capelin and herring and lower in the northeastern areas occupied by polar cod. Feeding success increased with the local abundance of capelin and polar cod. Capelin were a targeted prey, and cod fed efficiently on capelin in the areas where they overlapped. Herring overlapped with cod, but feeding success did not increase with herring abundance, suggesting that herring might escape predation. Although feeding success increased with local polar cod abundance, polar cod had a spatial refuge in the northeastern part, which cod did not enter. Our analyses imply that the cod were spatially constrained and that their prey differed in suitability.
\end{abstract}

KEY WORDS: Predator-prey interactions - Spatial anchors • Prey refuges · Ecosystem survey • Gadus morhua

\section{INTRODUCTION}

A central challenge for a predator is to optimize energy acquisition when prey are spatially and temporally heterogeneous (e.g. Armstrong \& Schindler 2011). This challenge includes optimizing spatial distribution relative to the distribution of prey. The ideal free distribution (IFD; Fretwell \& Lucas 1969) theory predicts a strong spatial association between predators and prey (Fauchald 2009). The IFD theory relies on many assumptions; among these is the assumption that prey are not responsive to the presence of predators. Furthermore, the only spatial heterogeneity considered in IFD is heterogeneity caused by prey patchiness; consequently there are no constraints imposed by the physical habitat on either predator or prey. Alternatively, the overlap between predator and prey distributions can be viewed as the outcome of a 2-way spatial game in which behavioural predator responses and anti-predator counter responses by prey are optimized (Sih 2005). The outcome of the game depends on how predators and prey are con- 
strained by factors other than the predator-prey interactions per se, the so-called spatial anchors (Sih 2005). In a heterogeneous environment, these include physiological adaptions to physical habitat characteristics (e.g. depth; Alonzo et al. 2003). Migration costs in terms of energy and time spent migrating to and from spawning grounds impose further spatial anchors (Fauchald 2009). When the prey are more constrained by the spatial anchor than the predator, the predator wins the spatial game, and there is spatial overlap between prey and predators. When the predators have a stronger spatial anchor than the prey, there is a negative or no association between predator and prey distributions (Sih 2005). A stronger spatial anchor for predators than prey might include narrower habitat tolerance, reducing spatial overlap and thus creating spatial refuges for the prey (e.g. Rose \& Leggett 1990).

Atlantic cod Gadus morhua are important predators in temperate and boreal shelf seas in the North Atlantic (Link et al. 2009). In these ecosystems, cod have the potential to shape the prey community and ecosystem functioning through top-down predation effects on lower trophic levels (e.g. Frank et al. 2005, van Leeuwen et al. 2008). However, due to heavy exploitation, the ecological role of cod has diminished in many ecosystems (Link et al. 2009). In contrast, the spawning stock biomass of cod inhabiting the Barents Sea (BS) is higher than during the 1950s, when the growth of the industrialized fishery started (Nakken 1998, ICES 2011). The BS cod stock is currently the largest in the world, and provides an excellent opportunity to study cod-prey interactions in a cod-dominated ecosystem.

Capelin Mallotus villosus are the main prey of cod in the northernmost ecosystems with cod (Link et al. 2009). Studies from other ecosystems have shown that cod are more constrained by temperature than capelin are. Due to the narrower thermal habitat niche, there are capelin refuges caused by thermal barriers or thermal habitats unsuitable for cod (Rose \& Leggett 1990, Ciannelli \& Bailey 2005). In the BS, constraints on cod-capelin overlap have not been explicitly studied in detail. However, the effect of capelin stock abundance fluctuations on fitness (growth, reproduction, cannibalism) of BS cod is well known and has been documented in a number of studies (e.g. Jørgensen 1992, Kjesbu et al. 1998, Yaragina \& Marshall 2000, Sandeman et al. 2008). The relationship between cod fitness and capelin stock biomass shows that capelin are highly suitable prey for cod. This is because capelin have a high energy content and probably also because the anti- predator behaviour of capelin is relatively inefficient (compared to e.g. herring; discussed by Johansen 2003). The capelin stock has collapsed and subsequently recovered 3 times during the last $30 \mathrm{yr}$ (Gjøsæter et al. 2009). The empirical relationships between cod fitness and capelin stock fluctuations also show that cod were unable to compensate for the loss of capelin during collapse by feeding on other prey. Nevertheless, the dependency of cod upon capelin has weakened in the last ca. $15 \mathrm{yr}$; whereas the first capelin stock collapse severely affected cod fitness, the effect of the last collapse was negligible (Gjøsæter et al. 2009). Gjøsæter et al. (2009) suggested that the reduced dependency upon capelin is caused by increased feeding on alternative prey. Furthermore, Gjøsæter et al. (2009) suggested that increased importance of other prey was determined by the recent warming of the BS (Levitus et al. 2009, Johannesen et al. 2012). One possible mechanism linking warming with importance of alternative prey is that increased temperatures reduce spatial constraints on cod.

In general, large numbers of potential alternative prey are available for cod. This is due to the large body size range of cod (maximum length $200 \mathrm{~cm}_{\text {; }}$ Cohen et al. 1990), large migration potential (>1000 km; Harden Jones 1968), wide temperature range $\left(-1.5\right.$ to $19^{\circ} \mathrm{C}_{;}$Righton et al. 2010) and broad diet (e.g. Link et al. 2009). In the BS, $>100$ different prey groups have been found in cod stomachs (Mehl 1991). The importance of other prey items in cod diet in the BS have been found to vary inter-annually as a function of capelin stock biomass (e.g. Orlova et al. 2005). In addition to capelin, the most important prey for BS cod include shrimp Pandalus borealis (Bogstad \& Mehl 1997, Berenboim et al. 2000), macrozooplankton (Bogstad \& Mehl 1997, Orlova et al. 2005), herring Clupea harengus (Johansen 2003) and polar cod Boreogadus saida (Orlova et al. 2009, Ajiad et al. 2011).

Here, we analysed for the first time a large-scale data set on cod distribution, diet and prey (capelin, juvenile herring, polar cod, shrimp and macrozooplankton) distribution sampled in late summer in the BS during recent warm years (2004 to 2009). Both capelin and cod exhibit seasonal northward feeding migrations (Fauchald et al. 2006, Hylen et al. 2008). The seasonal timing of our study coincides with the time of the year with the least ice cover and when the northward extent of the seasonal feeding migrations of capelin (Gjøsæter et al. 1998) and probably also cod (Hylen et al. 2008, Yaragina et al. 2011) reaches its maximum. We asked the following questions on the relationship between local prey abundance and cod 
abundance, displacement, diet composition and feeding success: (1) What is the spatial overlap between the distributions of cod and their prey? (2) How do cod displacements respond to changes in local prey abundance? (3) How does the local feeding success of cod vary with local prey abundance? (4) How does local prey consumption vary with local prey abundance?

These relationships between cod and prey may vary among the different prey species. Such differences will give us indications of the spatial constraint of cod relative to different prey, the suitability of the different prey, and to what extent cod target specific prey by changing their distribution relative to prey displacements.

\section{MATERIALS AND METHODS}

\section{Data acquisition}

Since 2004, the Institute of Marine Research (IMR, Norway) and the Polar Research Institute of Marine Fisheries and Oceanography (PINRO, Russia) have conducted the annual joint IMR-PINRO ecosystem survey (survey reports can be downloaded from www.imr.no). The years 2004 to 2009 were used in this study; those years were characterized by aboveaverage sea temperatures and below-average seaice coverage (Johannesen et al. 2012). During the study years, cod stock levels remained high, with a rising trend (average: $1.9 \times 10^{9}$ ind. $3 \mathrm{yr}$ of age or older, within a range 1.5 to $2.2 \times 10^{9}$ ind., ICES 2011). During the same period, the capelin stock changed from a state of collapse $\left(42 \times 10^{9}\right.$ ind. of $1 \mathrm{yr}$ old or older) to recovery $\left(571 \times 10^{9}\right.$ ind.),

During the ecosystem survey, each year 4 or 5 research vessels covered the whole ice-free part of the BS shelf and the Svalbard (Spitsbergen) shelf break ( 1.6 million $\mathrm{km}^{2}$ ) during August and September (Michalsen et al. 2011). The survey has evolved from several independent earlier surveys, covering parts of the BS, the most important being the international survey for 0-group fish (1965 to present), the acoustic survey for pelagic fish (1972 to present) and the shrimp survey (1981 to present).

During the ecosystem survey, ecosystem stations were taken every 30 to 40 nautical miles (n miles) in a regular grid. Each station consisted of (1) a CTD cast for temperature and salinity readings, (2) a bottom trawl haul and (3) a pelagic trawl haul. The CTD casts were set out on predetermined positions, and 1 trawl haul (pelagic or bottom) was performed on the way towards the station, and 1 haul was performed when leaving the CTD station (pelagic or bottom depending on which was taken first). Continuous acoustic registrations were made along the cruise tracks. In total, there were over 2000 ecosystem stations during the study period (2004 to 2009).

The bottom trawl gear was a Campelen 1800 shrimp bottom trawl with rockhopper gear. The mesh size was $80 \mathrm{~mm}$ (stretched) in the front and 16 to $22 \mathrm{~mm}$ at the cod end. The horizontal opening was $20 \mathrm{~m}$, and the vertical opening was 4 to $5 \mathrm{~m}$. The standard towing time was 15 min at 3 knots, equivalent to a towing distance of $0.75 \mathrm{n}$ miles, but hauls ranged from 5 min to $1 \mathrm{~h}$.

The pelagic trawl gear used was a Harstad trawl with a $20 \times 20 \mathrm{~m}$ mouth opening, 7 panels and a cod end. The mesh sizes of the panels ranged from $100 \mathrm{~mm}$ in the first panel to $30 \mathrm{~mm}$ in the last. The cod end consists of 3 nets of different mesh sizes, with the smallest being $7 \mathrm{~mm}$. The pelagic trawl was towed for standard time of $60 \mathrm{~min}$ (20 min each at the surface, $20 \mathrm{~m}$ and $40 \mathrm{~m}$, and additional tows deeper if there were hydro-acoustic registrations of 0-group fish farther down). This methodology was developed to obtain indices for 0-group fish and is detailed in Eriksen et al. (2009).

Index of local cod abundance

Cod abundance data were taken from the bottom trawl catches at the ecosystem stations, which were standardized to no. $\mathrm{n}$ mile ${ }^{-1}$ towed. The towing distance for the shortest hauls was set to $0.5 \mathrm{n}$ miles in order to avoid too high numbers, since there is a strong initial herding effect when trawling. All cod in the catch were counted and their lengths were measured to the nearest $\mathrm{cm}$ if the catch was not too large $(<500 \mathrm{~kg})$. In large catches, only a sub-sample was counted and measured, and the number of cod in the different length groups was estimated from the length proportions in the sub-sample.

Prey consumption

Cod stomach samples were taken from 1 cod per $5 \mathrm{~cm}$ length group per haul and analysed according to procedures described by Mehl \& Yaragina (1992). Prey from stomachs were identified to the lowest taxon possible, depending on the degree of digestion.

To estimate the individual consumption rate $C_{i}$ (g $\mathrm{d}^{-1}$ ) per cod for prey $i$, we used a stomach evacuation model (Temming \& Herrmann 2003) which was 
based on data obtained from laboratory experiments where cod were fed with prey species found in the BS (dos Santos \& Jobling 1992):

$$
C_{i}=24 \rho_{i} W^{0.305} \mathrm{e}^{0.11 T} S_{i}^{0.5}
$$

where $W$ is the body mass of the cod, $T$ is temperature $\left({ }^{\circ} \mathrm{C}\right.$, bottom temperature from the nearest CTD station), $S_{i}$ is the stomach content of prey $i$, and $\rho_{i}$ is the prey-specific evacuation constant, taken from Temming \& Herrmann (2003). This allowed us to correct for differences in digestibility among different prey types, slower digestion at low temperatures and slower digestion in large compared to small cod.

Temming \& Herrmann (2003) listed 10 prey categories (capelin, herring, polar cod, krill, shrimp, Trisopterus esmarkii, Hippoglossoides platessoides, Melanogrammus aeglefinus, Sebastes sp. and squid) found in our diet data (see Supplement 1 at www.intres.com/articles/suppl/m458p181_supp.pdf). For prey not included by Temming \& Herrmann (2003), we used the evacuation constant for the prey that we judged to be most similar (e.g. H. platessoides for all flatfish), or averages for all fish and crustaceans provided by Temming \& Herrmann (2003) for groups such as 'unidentified fish' and 'unidentified crustaceans'. We standardized the estimated consumption by dividing by predator weight and multiplying by 100 to obtain consumption as a percentage of body weight (see Bogstad \& Mehl 1997).

\section{Feeding success}

Following Bogstad \& Mehl (1997), we calculated total energy consumed in $\mathrm{kJ} \mathrm{d}^{-1} \mathrm{~g}^{-1}$ cod by multiplying the standardized consumption estimates of all prey with their corresponding prey-specific energy densities. By summing across all prey found in each cod stomach, we obtained a measure of feeding success ( $\left.\mathrm{kJ} \mathrm{d}^{-1} \mathrm{~g}^{-1} \mathrm{cod}\right)$. The energy density estimates were taken from Bogstad \& Mehl (1997) and Temming \& Herrmann (2003). These studies include the most important prey groups for cod. For prey groups not found in these papers, we used the energy densities of the most similar prey group or averages for all fish and crustaceans for groups such as 'unidentified crustaceans' and 'unidentified fish'.

\section{Indices of local prey abundance}

Capelin, polar cod and herring. Capelin, polar cod and juvenile herring are the most abundant pelagic fishes in the BS, which is the nursery area of Norwegian spring spawning (NSS) herring. Most herring in the $\mathrm{BS}$ are between 0 and $3 \mathrm{yr}$ old; when herring mature, they leave the BS and do not return. The main feeding area of mature NSS is the Norwegian Sea, and adult herring might enter the deeper western parts of the BS as part of extended feeding migrations. Capelin spawn along the northern coast of Norway and Russia in spring and exhibit densitydependent feeding migrations in summer (Fauchald et al. 2006). The polar cod is a true arctic species that has its whole life cycle within the BS. The main spawning areas are east of Svalbard (Spitsbergen) and between Novaya Zemlya and the Russian coast (Ajiad et al. 2011).

Hydro-acoustic data were used to obtain abundance spatial indices of capelin, polar cod and juvenile herring. Both Norwegian and Russian vessels were equipped with calibrated EK-60 echo sounders. Acoustic values (based on area backscattering coefficients) were allocated on the basis of the acoustic character of species and trawl samples at a resolution of 5 or $1 \mathrm{n}$ mile(s) (from 2008 and onwards). Pelagic trawl hauls were made in response to potential changes in the echo-sounder registrations in order to validate and support the allocation of acoustic values to species.

Zooplankton. Copepods are the most abundant group of zooplankton in the BS, but they are unimportant as prey for cod $1 \mathrm{yr}$ and older (Dalpadado \& Bogstad 2004, Dalpadado et al. 2009). The second and third most important groups of zooplankton in the BS are krill (4 regularly occurring species, see e.g. Zhukova et al. 2009) and pelagic amphipods (also called hyperiids) of the genus Themisto (e.g. Dalpadado et al. 2001).

We used catches of amphipods and krill from the pelagic 0-group hauls taken at the ecosystem stations to obtain spatial indices of abundance ( $\mathrm{kg} \mathrm{n} \mathrm{mile}{ }^{-1}$; Eriksen \& Dalpadado 2011). We tested for diurnal variation in catch rates for krill and amphipods, and found strong effects on krill and no effect on amphipods. Due to this strong diurnal vertical migration of krill, only night hauls could be used (see also Eriksen \& Dalpadado 2011), which reduced the data set by $2 / 3$. We therefore chose not to include krill in our analysis, although we recognise their importance as prey for cod (see 'Discussion' and Supplement 1).

Shrimp. Shrimp are abundant and widespread bentho-pelagic invertebrates in the BS, and their interaction with cod has been found to be important in many ecosystems (Worm \& Myers 2003) including the BS (Berenboim et al. 2000). Swept-area estimates 
of shrimp biomass $\left(\mathrm{kg} \mathrm{km}^{-2}\right)$ from bottom hauls were used to obtain spatial indices of abundance. These data were also used as input data in shrimp stock assessment (Hvingel 2006).

\section{Analyses}

Input data

Gridding. We projected all station data using the North Pole stereographic projection (central meridian $=35^{\circ} \mathrm{E}$, latitude of origin $\left.=75^{\circ} \mathrm{N}\right)$. We constructed a regular $35 \times 35 \mathrm{n}$ mile grid with 374 grid cells based on the survey design. The grid covered the BS shelf delimited by the $500 \mathrm{~m}$ depth contour towards the basins in the west and north (Fig. 1). Due to various problems (e.g. bad weather, ice, reduced survey time, technical difficulties), data were lacking from some of the grid cells in most years. In some years and grid cells, there was more than 1 station per grid cell (applies mostly to bottom trawl hauls); here stations were averaged by grid cell and year.

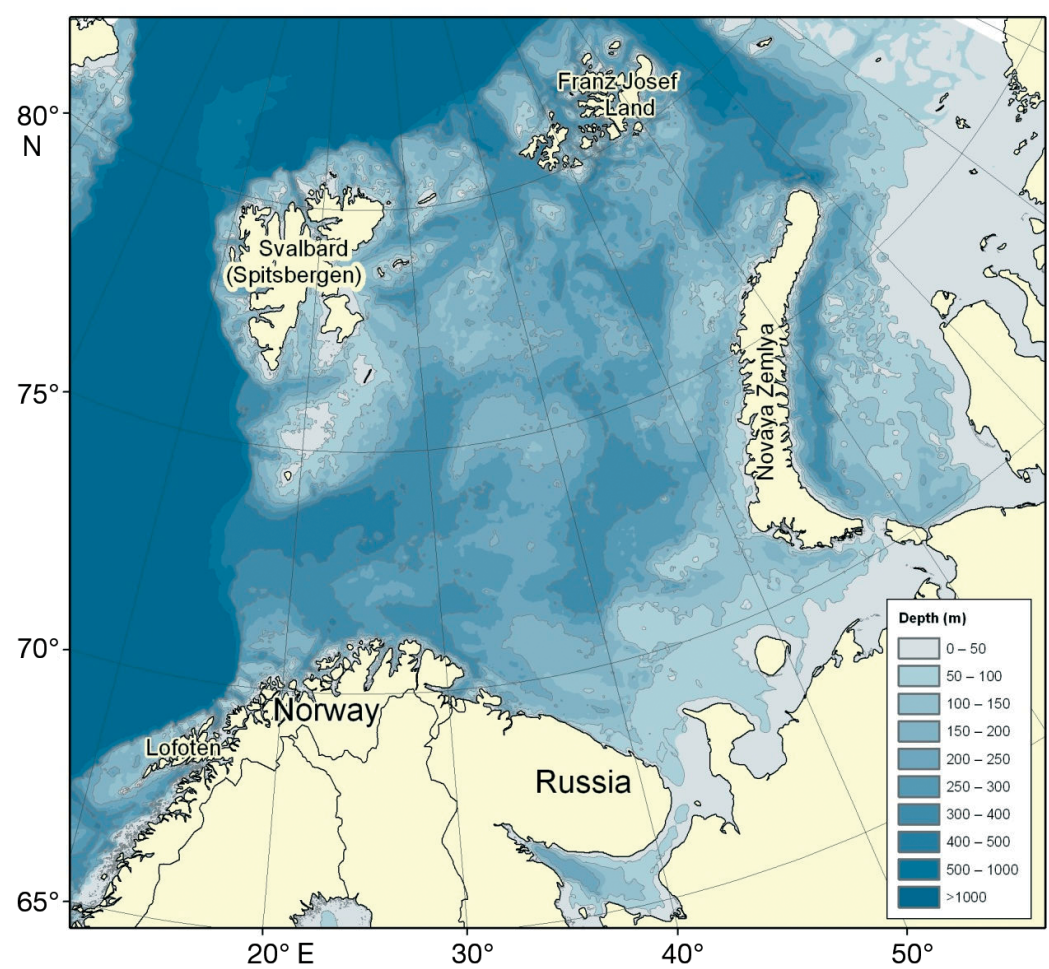

Fig. 1. Barents Sea (BS) shelf area $\left(\sim 1.6\right.$ million $\left.\mathrm{km}^{2}\right)$. The $500 \mathrm{~m}$ depth contour is used to delimit the BS towards the Greenland, polar and Norwegian Sea basin. Novaya Zemlya forms the border between the BS and the Kara Sea. Mature cod Gadus morhua spawn in the Lofoten area. Larvae drift with the Atlantic current into the nursery area in the BS
Response variables. We excluded data on cod $<30 \mathrm{~cm}$, since a high proportion of stomachs of small cod were empty or contained mostly krill and unidentified crustaceans (see Supplement 1). Furthermore, the catchability of small cod is poorer than that of larger cod. Before gridding data on feeding success and consumption, we first pooled the data by station. We did so by calculating station-specific averages by weighting each cod stomach sample by the proportion of cod from the same $5 \mathrm{~cm}$ length group, out of the total number of $\operatorname{cod} \geq 30 \mathrm{~cm}$ caught at the station. This was done to account for the length-stratified sampling scheme of the stomach data (1 sample per $5 \mathrm{~cm}$ length group per station, Bogstad et al. 1995). Then we averaged the stations by year and grid.

Predictors. Shrimp and amphipod abundance indices were gridded by averaging station data by grid cell and year. Grid cell depth was given by the average of the trawling depth of the bottom trawl stations in each grid cell.

Acoustic recordings of pelagic fish were assigned to an ecosystem station before gridding. Acoustic recordings of pelagic fish within a circle with a diameter of $30 \mathrm{n}$ miles around each ecosystem station were assigned to that station. The acoustic recordings within the circle were weighted with the inverse of the distance $d$ to the station $(1 /[1-d])$. The weights at each station were standardized so they summed to 1 . The assigned pelagic fish abundances were then averaged by grid cell and year.

\section{Statistical methods}

Spatial overlap between cod and prey. To investigate the spatial overlap between cod and prey we used general additive mixed models (GAMMs) because non-linear relationships between predators and prey could be expected. We modelled log-transformed cod abundance in each grid cell as a response to log-transformed abundance of prey species, using the mgcv package in R (Wood 2006). Year was included as a random factor to account for dependency between observations from the same year caused by systematic annual differences in the response variable. 
Cod displacement in response to changes in prey. To investigate how the year-to-year changes in the spatial distribution of cod were related to changes in the distribution of prey and changes in temperature, the local changes in abundance of cod from one year to another were related to the corresponding changes in prey abundance and bottom temperature. We expected the response to be most evident on relatively coarse spatial scales, and the data were accordingly aggregated on a $105 \times 105 \mathrm{n}$ miles ${ }^{2}$ grid . Abundance estimates of cod and prey were $\log _{10}(x+0.01)$-transformed prior to the analyses. Local (grid cell specific) year-to-year differences in abundance and temperature were calculated for all combinations of pairs of years. We assumed that the order of years was insignificant, and calculated the difference from a random order of years within each pair. Because grid cells where cod were absent in both years did not give any information regarding the change in the distribution of cod, these observations ( 7 out of 525) were removed.

We assumed a positive response (increased local cod abundance) to increased local prey abundance, irrespective of initial prey abundance. In contrast, given an existing optimal temperature range for cod, we expected the response to a change in temperature to be dependent on initial temperature. Specifically, under cold initial conditions, we expected a positive response to a rise in temperatures, while under warm initial conditions we expected a negative response. An interaction term between initial temperature and change in temperature was therefore included in the analyses. Year-to-year differences in the total abundance of cod were expected to make systematic differences in the response variable according to the year. To control for this variation, we included year (the first year in the subtraction) as a random factor in the analyses. Initial analyses indicated linear relationships. The relationships were therefore modelled by a linear mixed-effect model (LME), using the NLME package in R (Pinheiro et al. 2006).

Effect of prey abundance on feeding success. To investigate the effect of prey abundance on cod feeding success, we used GAMMs because non-linear relationships between predators and prey could be expected. We modelled square root-transformed feeding success in each grid cell as a response to log-transformed abundance of prey species, using the mgcv package in R (Wood 2006). Year was included as a random factor to account for dependency between observations from the same year caused by systematic annual differences in the response variable.
Relationship between consumption and local prey abundance. To explore functional relationships between cod consumption and prey abundance, we applied constrained ordination analyses (Legendre \& Legendre 1998), which is similar to multivariate linear regression. In this type of analysis, the proportion of the variation in the response variables (consumption of each prey) explained by the predictors (here the local indices of prey abundance) is of interest. We used multivariate statistics to account for covariation among response variables. The choice of multivariate model used to describe the predator-prey relationship was based on the comparison of eigenvalues from a redundancy analysis and a canonical correspondence analysis (CCA); this was done in order to determine whether the response variables displayed a linear or unimodal response to the predictor gradients (Legendre \& Anderson 1999, Corfield 2000). The eigenvalues derived from these analyses (not presented here) suggested that the response variables display a predominately unimodal response to the predictor gradients, hence the use of CCA. The response variables in this analysis were mean consumption ( $\mathrm{g} \mathrm{d}^{-1} \mathrm{~g}^{-1} \mathrm{cod}$ ) of prey (capelin, herring, polar cod, amphipods or shrimp) in each grid cell and year, and the predictors were the local abundance indices of those prey species in the same grid cell and year. A significant positive association between the response and predictor variables implies that prey consumption increases with increasing prey abundance. In order to reduce the effect of outliers, the response and predictor variables were log-transformed prior to analysis. Each predictor variable (prey species) was tested by forward selection and 1000 Monte Carlo permutations; only variables significant at the $5 \%$ level were considered important.

\section{RESULTS}

\section{Prey distributions}

Local abundance of some of the prey species overlapped (Figs. $2 \& 3$, Table 1), but the level of collinearity between the predictors (prey, depth and temperature) was acceptable for our choice of statistical analysis method (Zuur et al. 2009). This was judged from the variance inflation factors $\left(\mathrm{VIF}=1 / 1-R_{i}^{2}\right.$ where $i$ is the predictor, and $R_{i}^{2}$ is from the regression of predictor $i$ as a function of all the other predictors) which were all $<3$, for all predictors. 


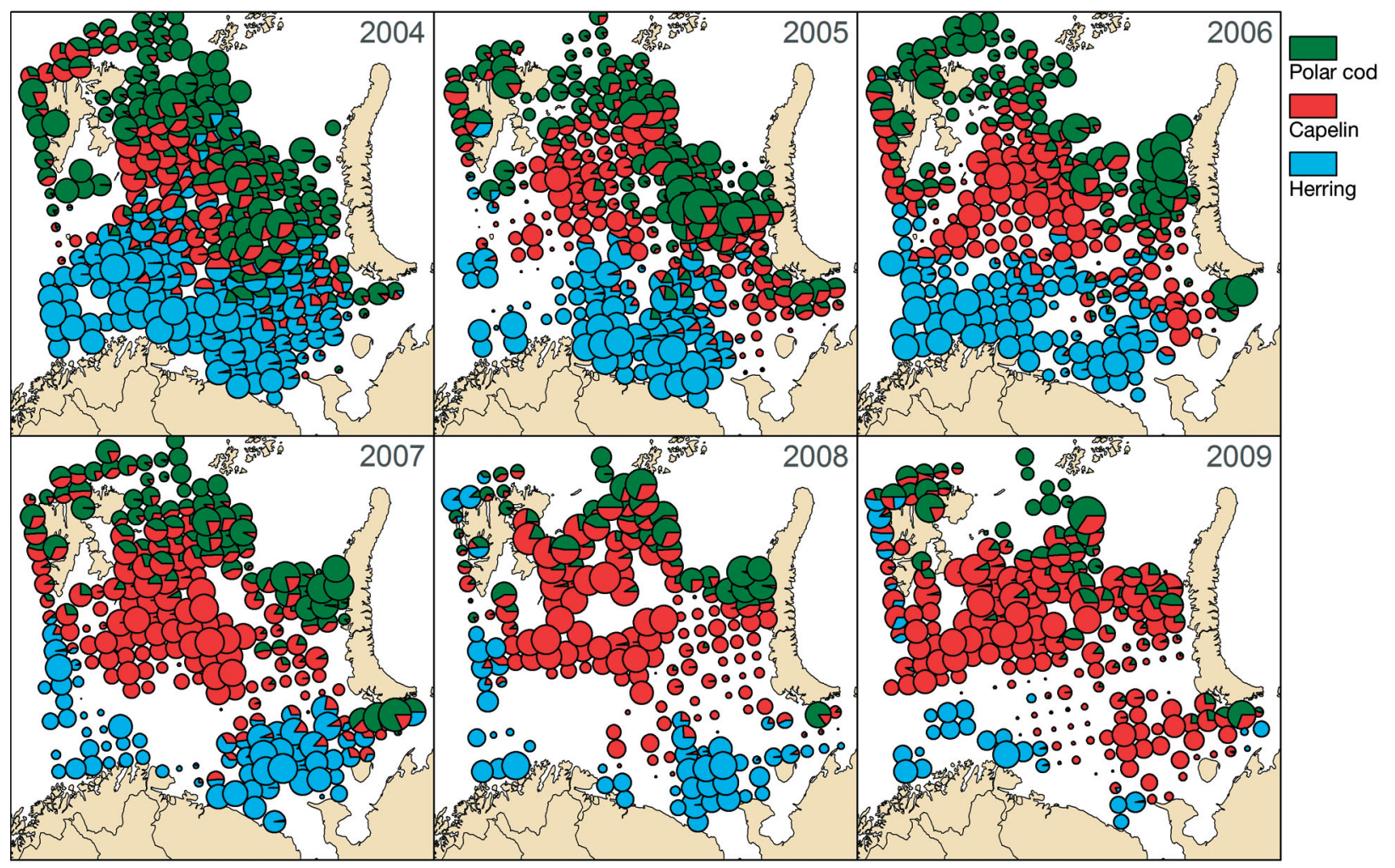

Fig. 2. Acoustic registrations (backscattering coefficients) of pelagic fish by year. The size of the pie is proportional to the sum of the registrations, but the sizes are not comparable across years

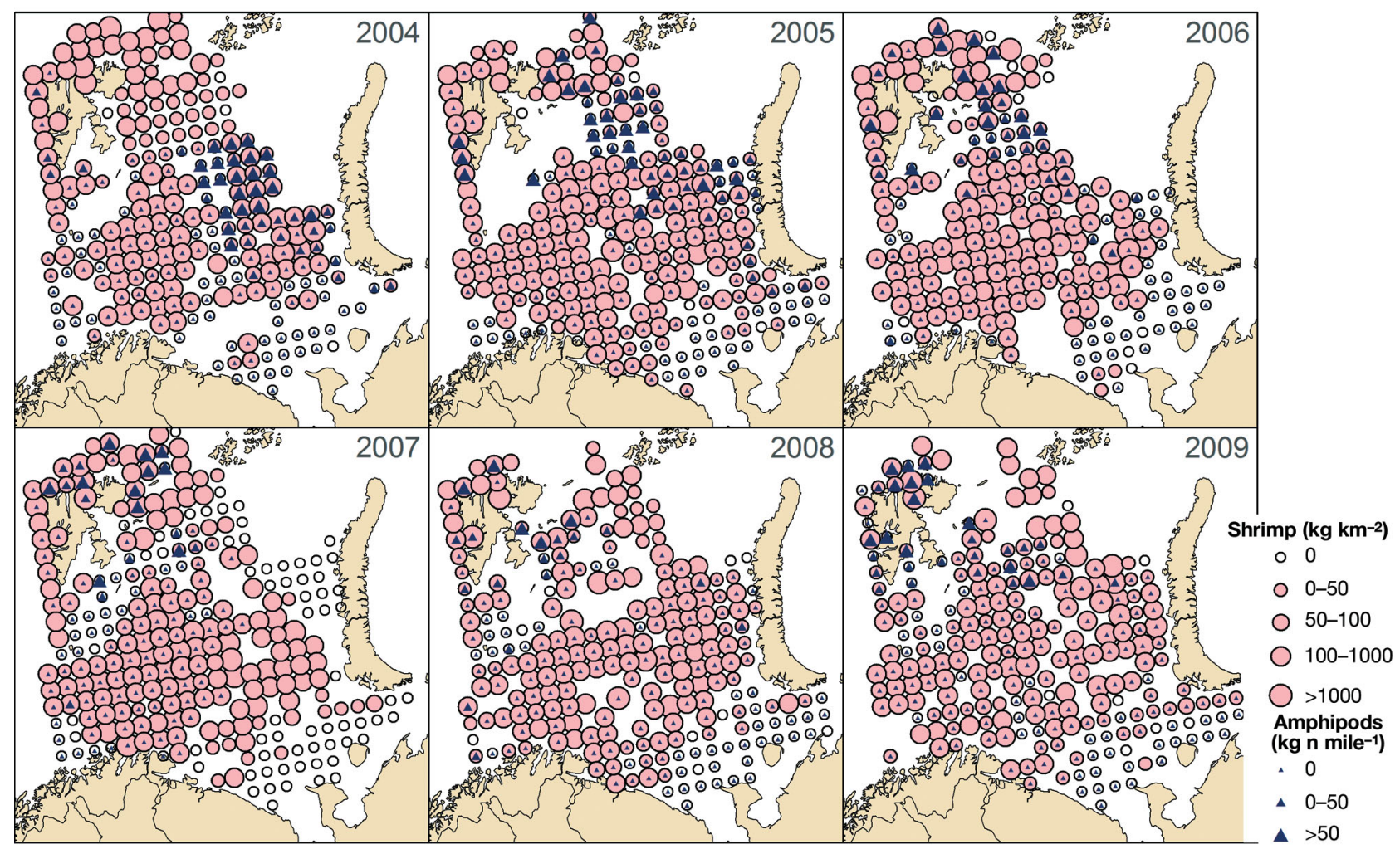

Fig. 3. Pandalus borealis and Themisto spp. Shrimp abundance (white and pink bullets proportional to $\mathrm{kg}^{\mathrm{k}} \mathrm{km}^{-2}$ ) and amphipods (kg n mile ${ }^{-1} ; \mathbf{\Delta}$ : small $=0$ registration, large = registrations of amphipods) by year. $P$. borealis (shrimp) data were not registered in all hauls, and Themisto spp. (amphipods) data were lacking in the north in 2004 and east in 2007 
Table 1. Pearson correlation coefficients between cod prey items abundance, depth and temperature (Temp). Significant relationships at the 0.05 level are in bold

\begin{tabular}{|lcccrc|}
\hline & Capelin & Herring & Polar cod & Shrimp & Amphipods \\
\hline Temp & $\mathbf{- 0 . 5 4}$ & $\mathbf{0 . 4 4}$ & $\mathbf{- 0 . 3 4}$ & $\mathbf{- 0 . 1 4}$ & $\mathbf{- 0 . 2 5}$ \\
Depth & $\mathbf{- 0 . 1 1}$ & $\mathbf{0 . 2}$ & 0.02 & $\mathbf{0 . 4 0}$ & 0.05 \\
Capelin & & $\mathbf{0 . 3 7}$ & $\mathbf{0 . 1 4}$ & 0.04 & 0.06 \\
Herring & & & $\mathbf{- 0 . 2 0}$ & -0.07 & $\mathbf{- 0 . 2 0}$ \\
Polar cod & & & & 0.07 & $\mathbf{0 . 4 3}$ \\
Shrimp & & & & & -0.0 \\
\hline
\end{tabular}

\section{Spatial overlap between cod and prey}

Cod were widely distributed on the BS shelf, except in its most northeastern parts between Franz Josef Land and Novaya Zemlya and in deeper areas (Fig. 4). We found a positive spatial overlap between cod and both capelin and herring (Table 2, Fig. 5). The spatial relationships between cod, and polar cod,

The correlation was strongest between amphipods and polar cod, both of which are mainly found in the north (Figs. 2 \& 3). Capelin were found mainly in the frontal areas where Atlantic and Arctic water meet, which is south of the main polar cod and amphipod distributions (Fig. 2). However, capelin had a stronger negative correlation with temperature than polar cod or amphipods did (Table 1). Juvenile herring were found in the southeast, while in the west, adult herring entered the deeper parts of the BS from the Norwegian Sea as part of their feeding migration. Shrimp were widespread, except in the shallower bank areas. shrimp and amphipods were all negative. Depth was positively correlated with shrimp (Table 1), and when depth was included as a co-variate together with shrimp in the GAMM, the negative effect of shrimp on cod abundance became non-significant (Table 2), whereas the other relationships remained unchanged.

The effect of depth on cod abundance was nonlinear and generally negative, as cod were mostly found in shallow areas $(<150 \mathrm{~m}$, Fig. 5). Depth was the most important predictor of local cod abundance (Table 2).

In summary, the analyses showed that cod occupied shallow areas with high abundances of capelin

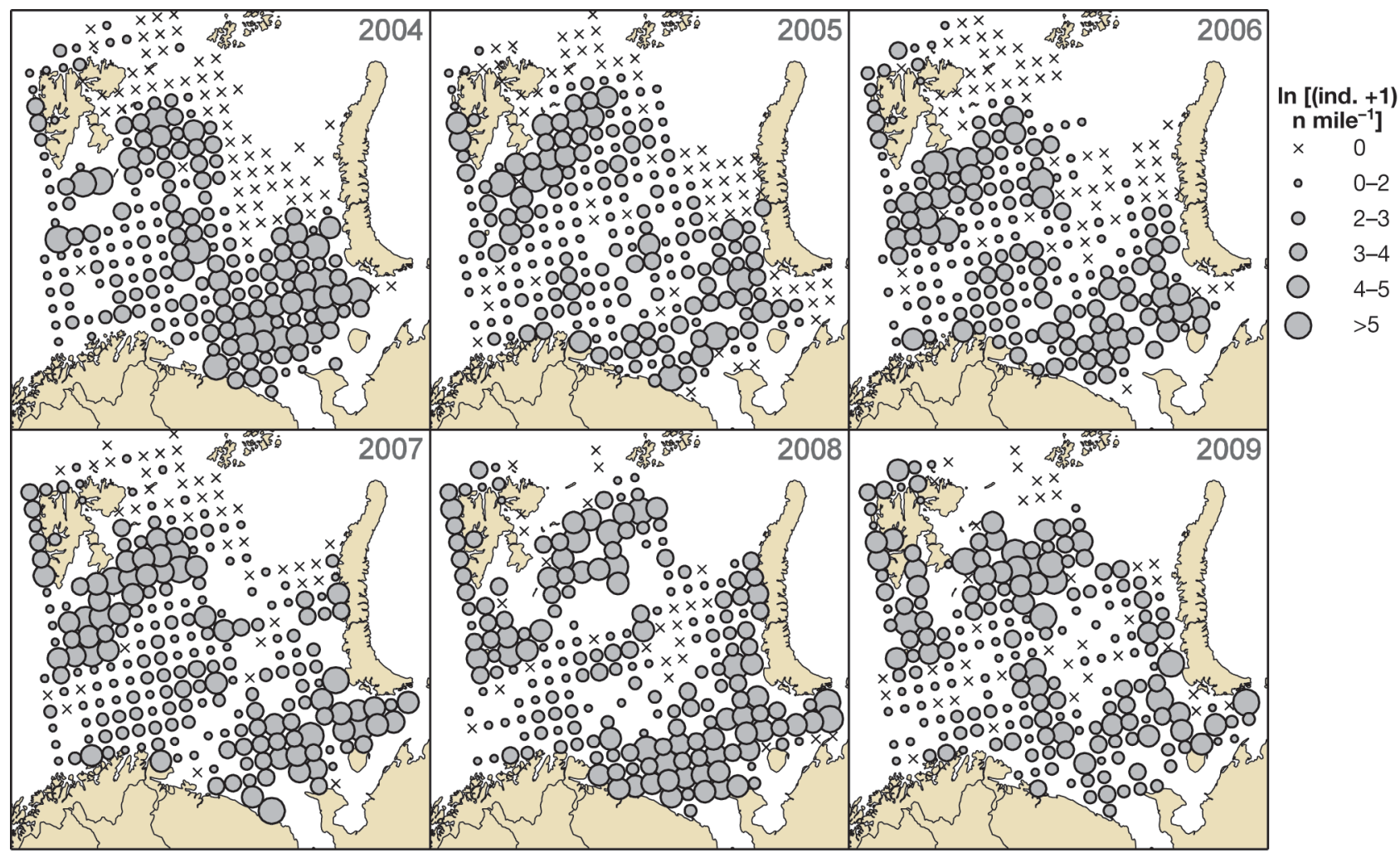

Fig. 4. Gadus morhua. Cod abundance by year (grey bullets proportional to log [(ind. +1) nautical mile $\left.{ }^{-1}\right]$ 
Table 2. Gadus morhua. General additive mixed-effect model relating local abundance of $\operatorname{cod} \geq 30 \mathrm{~cm}$ to local abundance of capelin Mallotus villosus, polar cod Boreogadus saida, herring Clupea harengus, shrimp Pandalus borealis and amphipods Themisto spp. (fixed effects) and year (random effect). The relationship with shrimp was non-significant when depth was included in the model, but was significant when depth was excluded (shown in parentheses). Sample size $=1105$, levels of random effect (years) $=6$. Edf: estimated degrees of freedom

\begin{tabular}{|lccc|}
\hline Parameter & Edf & $F$ & $\mathrm{p}$ \\
\hline Capelin & 1 & 28.03 & $<0.0001$ \\
Polar cod & 1 & 23.74 & $<0.0001$ \\
Herring & 1 & 7.08 & 0.002 \\
Shrimp & $2.3(2.2)$ & $1.99(60.5)$ & $0.13(<0.0001)$ \\
Amphipods & 1 & 16.35 & $<0.0001$ \\
Depth & 4.5 & 30.33 & $<0.0001$ \\
Random effect & & & \\
Between-year SD $=0.10$ & & \\
Within-year SD (residuals) & $=0.55$ & \\
\end{tabular}

and herring and avoided the northeastern areas with high abundances of amphipods and polar cod, and the deeper areas with shrimp.

\section{Displacement in response to changes in prey}

Interannual changes in the local abundance of cod were positively associated with changes in the abundance of capelin and herring, suggesting that cod responded positively to increases in the abundance of these species (Table 3, Fig. 6). Interestingly, we found a weak negative response to changes in the abundance of amphipods. No significant relationship was found for polar cod or shrimps. A significant response was found with respect to the interaction between the initial bottom temperature and the change in bottom temperature; while this relationship turned weakly negative under warm initial conditions, it was positive when the initial temperature was low. The strong response under cold initial conditions and weak response under warm conditions is in accordance with the fact that the BS is the northern limit for the distribution of cod.

\section{Effect of prey abundance on feeding success}

Local feeding success was positively associated with the local abundance of capelin and polar cod

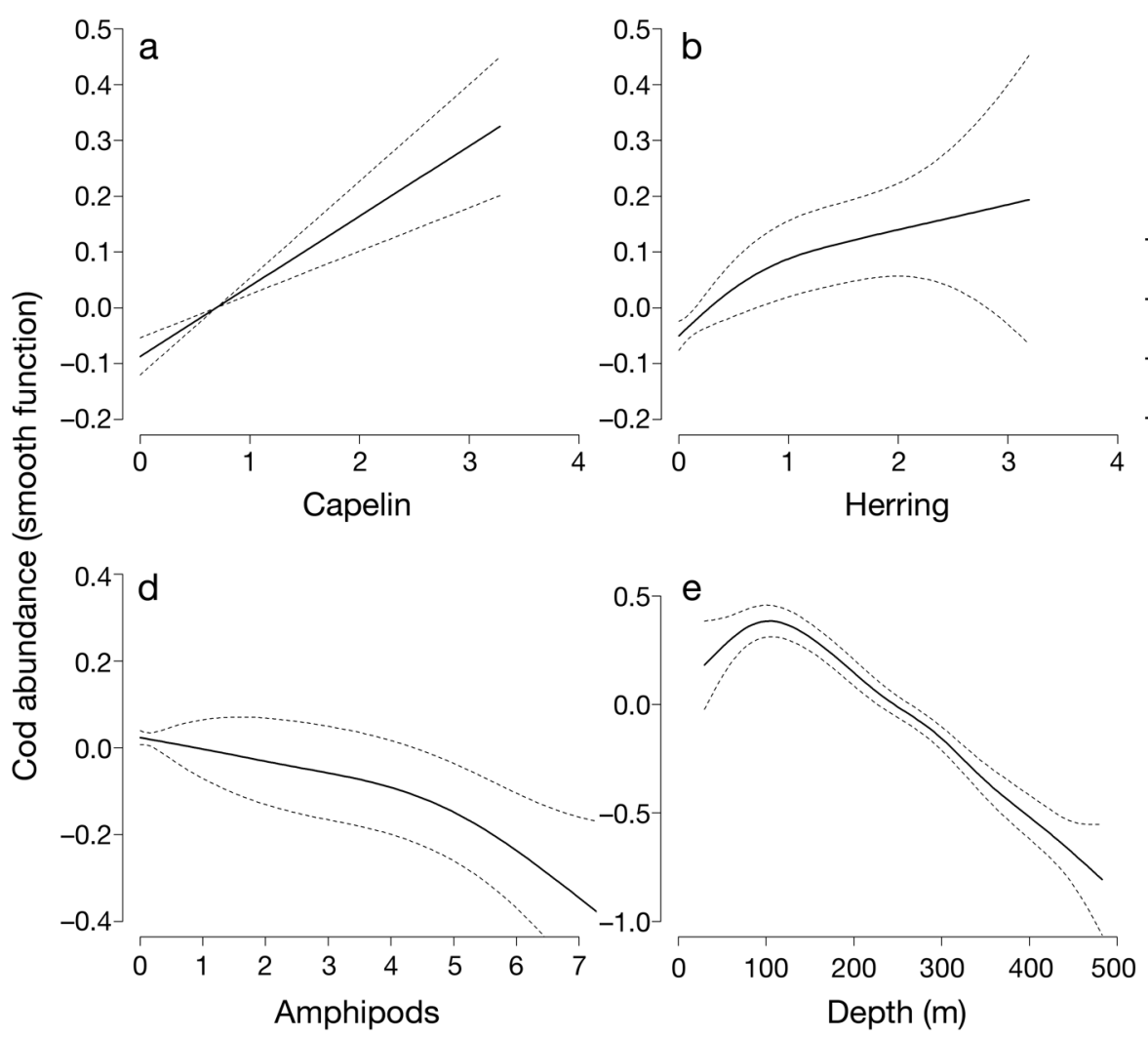

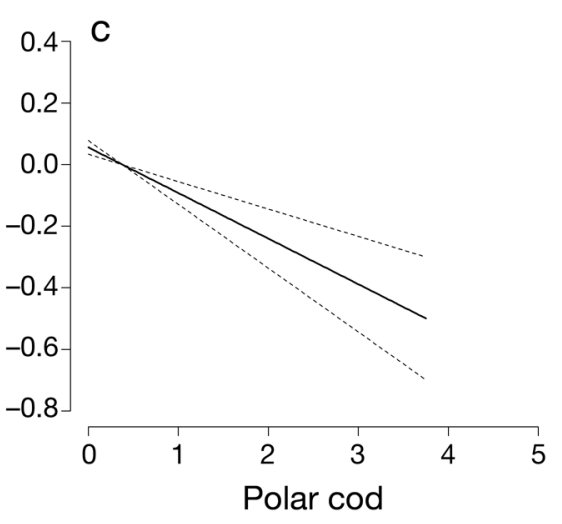

Fig. 5. Gadus morhua. Partial plots of smooth function from a general additive mixed-effect model of the predicted relationship between cod abundance and significant prey (a) capelin Mallotus villosus, (b) herring Clupea harengus, (c) polar cod Boreogadus saida, (d) amphipods Themisto spp. and (e) depth. Year was included as a random factor. Dashed lines $=$ SE envelopes 
Table 3. Gadus morhua. Linear mixed-effect models, relating interannual changes in the local abundance of cod to changes in different prey species and bottom temperature. Sample size $=518$ observations, levels of random effect (years) $=6$. InitTemp: initial temperature

\begin{tabular}{|lrrr|}
\hline Parameter & Value & SE & \multicolumn{1}{c|}{$\mathrm{p}$} \\
\hline Fixed effects & & & \\
Intercept & -0.030 & 0.084 & 0.718 \\
$\Delta$ Capelin & 0.099 & 0.022 & $<0.001$ \\
$\Delta$ Polar cod & 0.041 & 0.022 & 0.061 \\
$\Delta$ Herring & 0.064 & 0.014 & $<0.001$ \\
$\Delta$ Shrimps & -0.032 & 0.025 & 0.206 \\
$\Delta$ Amphipods & -0.023 & 0.012 & 0.048 \\
$\Delta$ Temperature & 0.194 & 0.032 & $<0.001$ \\
InitTemp & -0.005 & 0.012 & 0.712 \\
$\Delta$ Temp $\times$ InitTemp & -0.043 & 0.012 & $<0.001$ \\
Random effect & & & \\
Among-year SD = 0.187 & & \\
Within-year SD (residuals) $=0.506$ & & \\
\hline
\end{tabular}

(Table 4, Fig. 7). No significant relationship was found between feeding success and the abundance of amphipods or herring (Table 4). We found a negative relationship between feeding success and the local abundance of shrimp. However, depth was positively correlated with shrimp (Table 1), and when depth was included together with shrimp in the GAMM, the effect of shrimp on feeding success became non-significant (Table 4). The effect of depth on feeding success was negative and almost linear (Fig. 7).
Table 4. Gadus morhua. General additive mixed-effect model of the effect on feeding success of $\operatorname{cod} \geq 30 \mathrm{~cm}$ of local abundance of capelin Mallotus villosus, polar cod Boreogadus saida, herring Clupea harengus, shrimp Pandalus borealis and amphipods Themisto spp. (all fixed effects) and year (random effect). The relationship with shrimp was nonsignificant when depth was included in the model, but was significant when depth was excluded (shown in parentheses). Sample size $=885$, levels of random effect $($ years $)=6$. Edf: estimated degrees of freedom

\begin{tabular}{|lccc|}
\hline Parameter & Edf & $F$ & $\mathrm{p}$ \\
\hline Capelin & 2.29 & 10.19 & $<0.0001$ \\
Polar cod & 1 & 11.34 & 0.0008 \\
Herring & 1.58 & 0.39 & 0.63 \\
Shrimp & $1.00(1.73)$ & $2.09(27.5)$ & $0.15(<0.0001)$ \\
Amphipods & 1.31 & 0.33 & 0.63 \\
Depth & 1.01 & 26.57 & $<0.0001$ \\
Random effect & & \\
Between-year SD = 0.09 & \\
Within-year SD (residuals) $=0.60$ & \\
\multicolumn{4}{l}{} \\
\hline
\end{tabular}

\section{Relationship between consumption and local prey abundance}

The consumption of capelin, amphipods, polar cod, shrimp and herring by cod reflected in general the spatial distribution of these prey (cf. Figs. 2, $3 \& 8$ ). This was corroborated by the CCA, since all prey predictors were significant and positively correlated with the corresponding response variables (Fig. 9). This implies that each of the prey-specific consumption rates rose with increasing prey abundance of the same prey species.

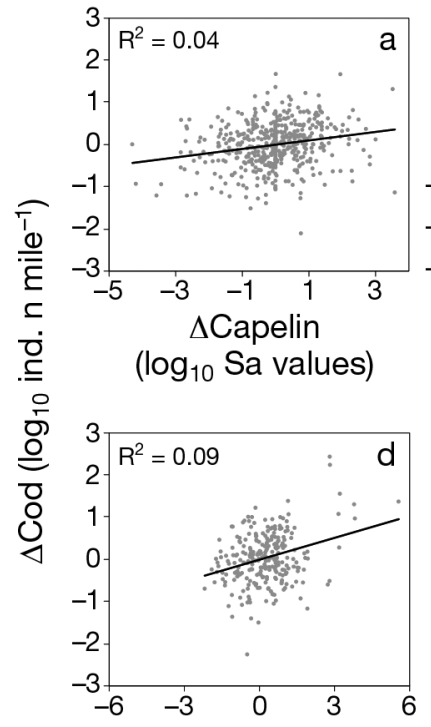

$\Delta$ Temperature $\left({ }^{\circ} \mathrm{C}\right)$ (low initial temperature)
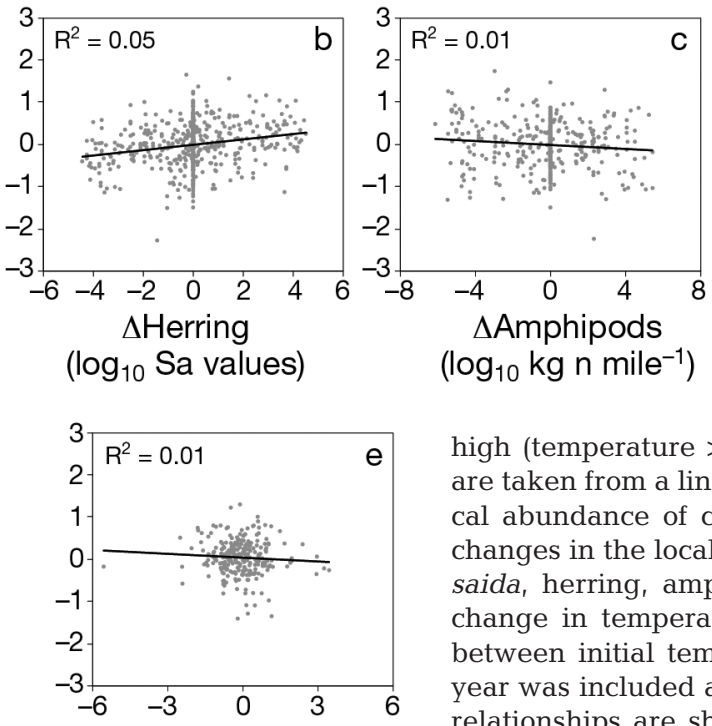

$\Delta$ Temperature $\left({ }^{\circ} \mathrm{C}\right)$ (high initial temperature)
Fig. 6. Gadus morhua. Partial residual plots of the relationships between the year-to-year changes in the local abundance of cod and the corresponding changes in the local abundance of (a) capelin Mallotus villosus, (b) herring Clupea harengus and (c) amphipods Themisto spp. The effect of a rise in temperature was (d) positive when the initial temperature was low (temperature $\leq$ median temperature) and (e) weakly negative when the initial temperature was high (temperature $>$ median temperature). The partial residuals are taken from a linear mixed-effect model with change in the local abundance of cod as response variable. Fixed factors were changes in the local abundance of capelin, polar cod Boreogadus saida, herring, amphipods and shrimp Pandalus borealis, local change in temperature, initial temperature and the interaction between initial temperature and change in temperature. Initial year was included as a random factor. Only significant $(p<0.05)$ relationships are shown. The changes in the abundance of cod and prey were calculated from $\log _{10}(x+0.01)$-transformed abundance data 

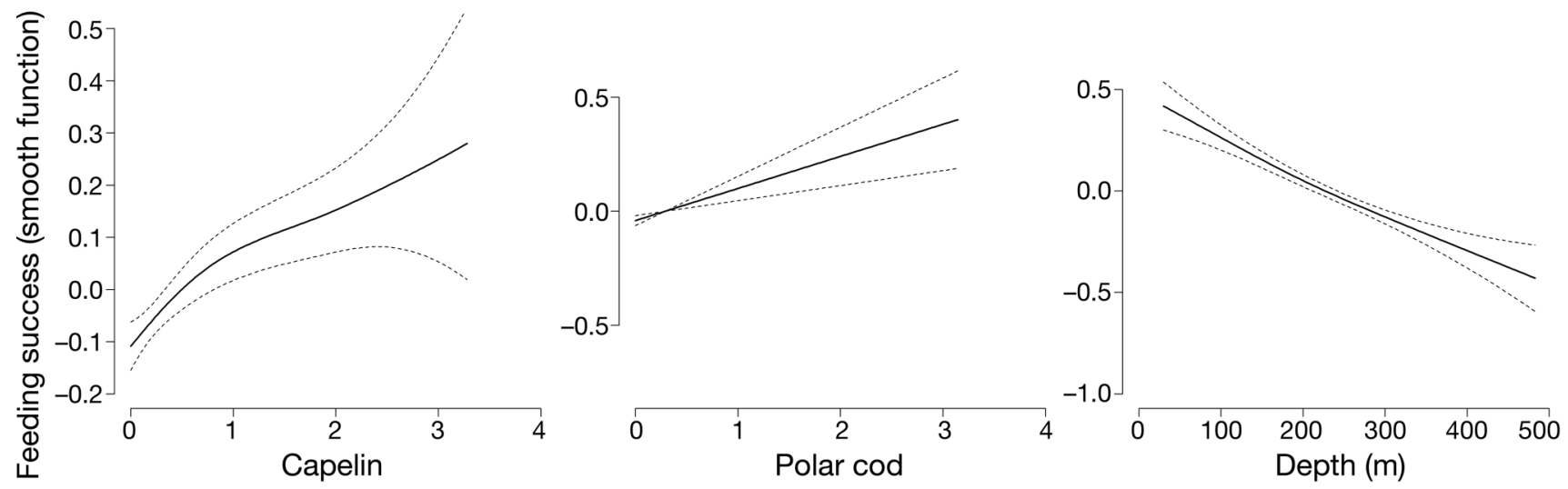

Fig. 7. Gadus morhua. Partial plots of smooth function from a general additive mixed-effect model of the predicted relationship between cod feeding success and significant prey capelin Mallotus villosus, polar cod Boreogadus saida, and depth. Year was included as a random factor. Dashed lines $=\mathrm{SE}$ envelopes

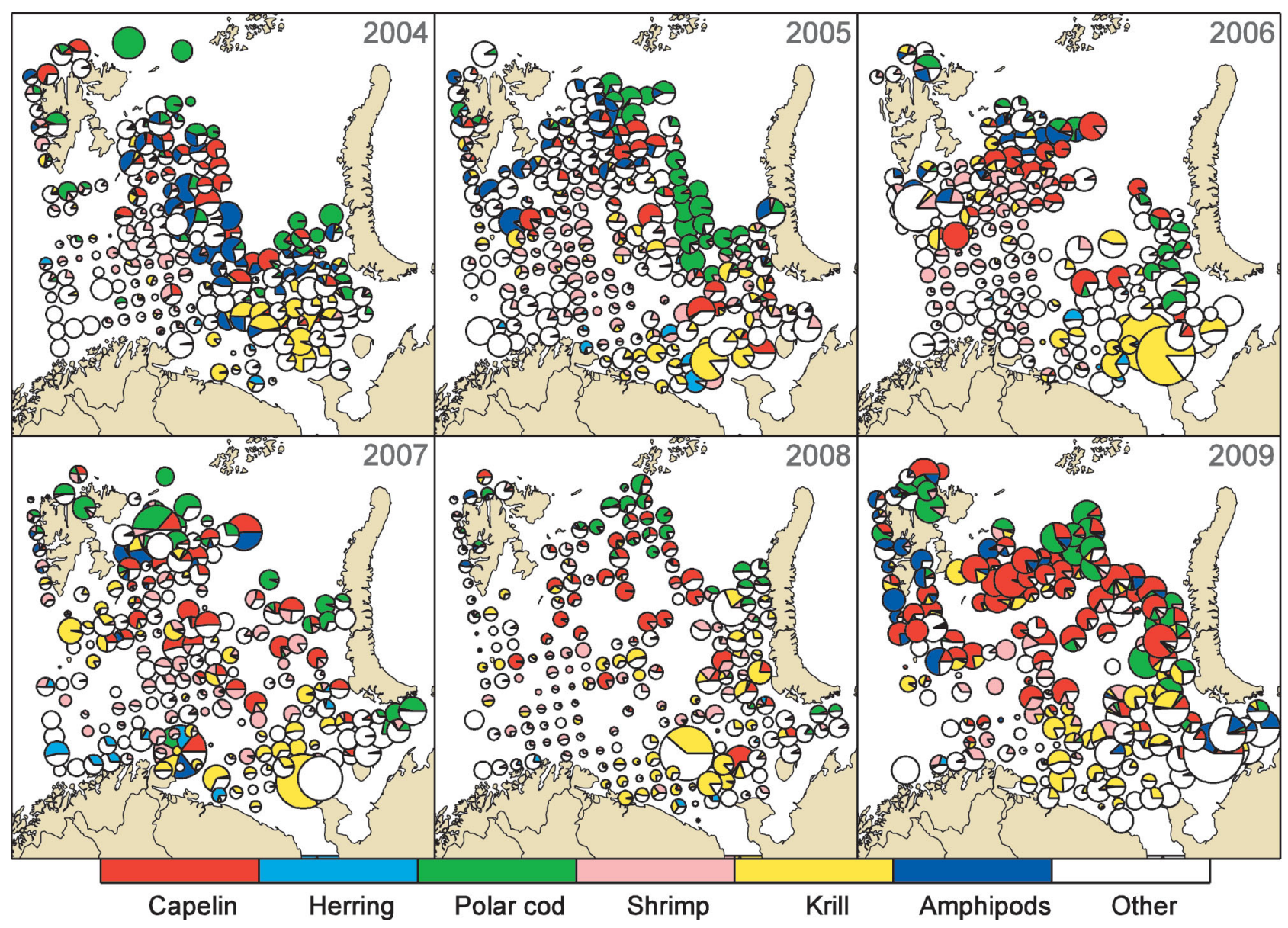

Fig. 8. Gadus morhua. Pie charts of diet composition of cod by year. The size of the pie is proportional to individual consumption of all prey types, but the sizes are not comparable across years

The CCA revealed that together; the predictors (local prey abundance indices) explained $25.8 \%$ of the total variation in consumption of the focal prey (Fig. 9). The first 2 axes explained $55 \%$ of the con- strained variation. The biomass of polar cod and capelin were the 2 most important predictors, explaining 9.2 and $7 \%$, respectively, of the total variation in food consumption by cod. 


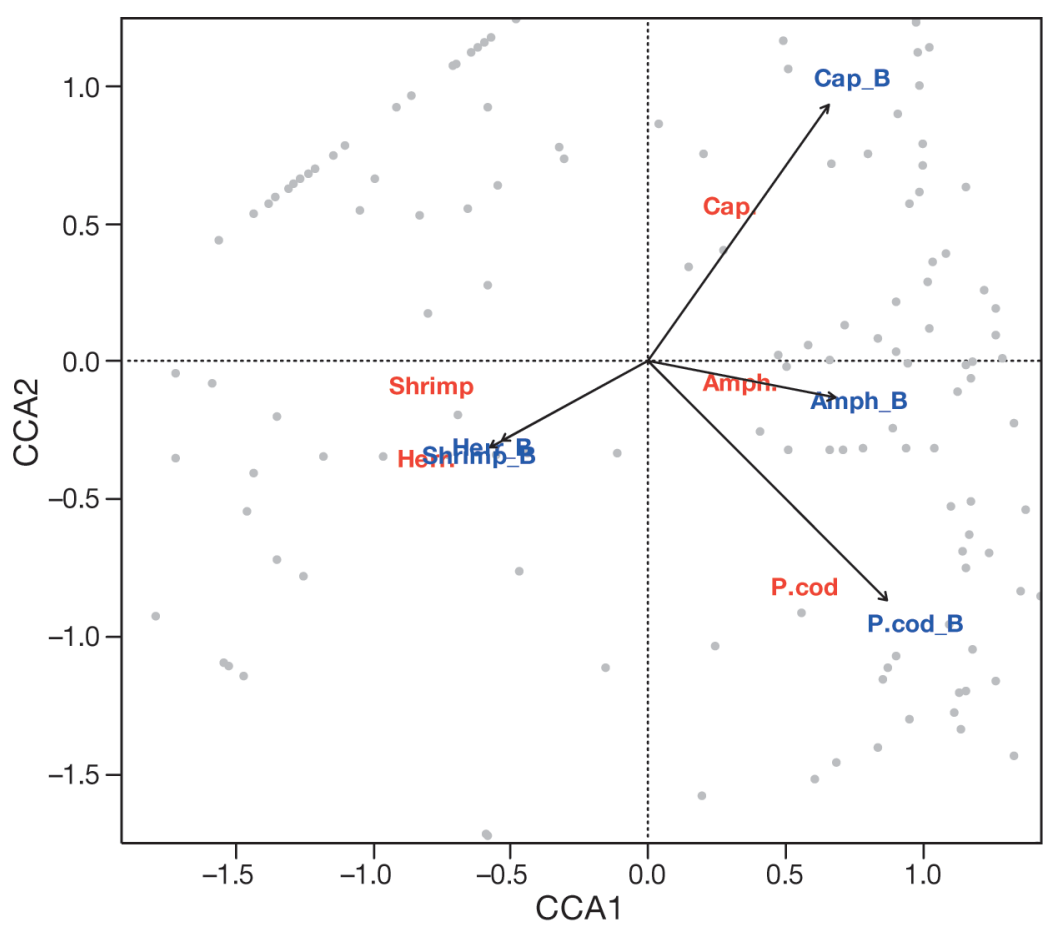

Fig. 9. Canonical correspondence analysis (CCA) ordination biplot of axes 1 and 2 with grid cells (grey dots), consumed prey species (red) and significant prey predictors (blue). The length of the arrows can be interpreted as a measure of covariation between response and predictors

\section{DISCUSSION}

\section{Cod-prey interactions} in a heterogeneous environment

Our results suggest that constraints on cod and suitability of prey differed among the prey investigated (Table 5). Although cod responded positively to polar cod both with respect to diet and feeding success (Figs. 7 \& 9), the relationship between local abundance of cod and polar cod was negative (Fig. 5), and cod generally avoided the northeastern area occupied by polar cod (Figs. $2 \& 4$ ). This sug-

Table 5. Gadus morhua. Influence of local prey abundance on local cod abundance (spatial overlap), interannual changes in distribution (displacement), energy consumed per gram cod (feeding success) and diet composition (proportion of prey in diet, PPD). +/-: positive/negative significant effects; 0: nonsignificant effects (sign in parentheses shows effect when depth was excluded from models in Tables $2 \& 4$ )

\begin{tabular}{|lccccc|}
\hline & Capelin & Polar cod & Herring & Shrimp & Amphipods \\
\hline Spatial overlap & + & - & + & $0(-)$ & - \\
Displacement & + & 0 & + & 0 & - \\
Feeding success & + & + & 0 & $0(-)$ & 0 \\
PPD & + & + & + & + & + \\
\hline
\end{tabular}

gests that although polar cod were a suitable prey item, they had a refuge in the northeastern area that cod were reluctant to enter.

In contrast, cod overlapped with herring (Fig. 5). However, the responses of cod to herring with respect to diet were weak, and there was no effect of herring abundance on feeding success (Fig. 7). This suggests that herring were largely able to escape predation, possibly through local avoidance mechanisms, e.g. vertical separation of herring and cod (Orlova et al. 1995). In the area where cod and herring overlapped, krill were an important prey of cod (Fig. 8; Orlova et al. 2005). Herring are also an important and very efficient predator of krill in the BS (Hallfredsson \& Pedersen 2009). Thus in the southeastern BS where cod and herring overlap they are probably competitors, and their positive spatial association might be because both aggregate on krill. However, we do not have reliable data to confirm this speculation, and to confirm the presence of large concentrations of krill during summer in the southeastern BS. However, high concentrations of krill were found in these areas in November to December (2000 to 2005, Zhukova et al. 2009).

Two other prey groups, amphipods and shrimps, had limited overlap with cod. Furthermore, cod displayed either negative or no responses to these prey, with respect to feeding success and spatial displacement, suggesting that amphipods and shrimp were not targeted as prey. In an earlier BS study (Bogstad \& Mehl 1997, data mainly from winter), amphipods and shrimp ranked as the second and third most important prey of cod (after capelin). Cod predation is a regulator of shrimp abundance in several ecosystems (Worm \& Myers 2003), but the evidence in the BS is ambiguous (Berenboim et al. 2000, Hvingel 2006). Poor data quality (amphipods) and constraints on cod imposed by depth (shrimp) as well as low prey suitability due to low energy density (Bogstad \& Mehl 1997) could be important in explaining the lack of or negative responses of cod to amphipods and shrimp. 
At the resolution of our study (35 × $35 \mathrm{n}$ miles), local cod diet reflected the local abundance of prey, suggesting that feeding was opportunistic and consistent with generalist predation. Still, the abundance of cod was higher in areas with capelin and herring, and cod distribution changed in response to these prey. Therefore, cod appear to select prey by adjusting their distribution relative to the distribution of prey. Furthermore, although cod are generalist predators (Link \& Garrison 2002), we found that feeding success, spatial overlap and displacement varied according to prey type. All of these factors positively matched capelin abundance, so that the only prey species found to have unequivocally positive predator-prey relationships was capelin (Table 5).

\section{Capelin-cod interaction}

The interaction between capelin and cod might be constrained by temperatures both at large and small scales. On a large scale (>100 km), Ciannelli \& Bailey (2005) found that the Pacific cod Gadus macrocephalus and capelin overlap was determined by inter-annual differences in thermal conditions; in cold years, a cold-water basin prevented cod from entering the main distribution area of capelin. At scales of $20 \mathrm{~m}$ to $10 \mathrm{~km}$, the spatial overlap between cod and capelin was found to be elusive (Horne \& Schneider 1994), and oceanographic processes might create temperature variations at a scale of 2 to $3 \mathrm{~km}$ that create short-term thermal refuges for capelin (Rose \& Leggett 1990).

We did not study small-scale processes and found no evidence of constraints at a larger scale. Cod fed successfully on capelin where the species overlapped, and cod aggregated in areas with high capelin abundance. We thus conclude that the influence of temperature on the interaction between capelin and cod in the summer feeding season was not important under the current warm conditions in the BS.

However, Yaragina et al. (2003) stated that in colder years, BS cod do not reach the main capelin distribution areas during summer migrations. The results of Yaragina et al. (2003) are based on diet data from Russian commercial vessels and the Russian literature (e.g. Zatsepin \& Petrova 1939). Since these data are not part of a consistent time series, it is difficult to directly test for the effect of interannual temperature variation on cod-capelin overlap in summer.

\section{What are the spatial anchors of cod?}

We found that depth was an important determinant of both the spatial distribution and feeding success of cod, which implies that depth is an important spatial anchor for cod. Depth limited the shrimp-cod overlap and thus the importance of shrimp as prey for cod. Light declines with depth, decreasing the visual reaction distance of fishes, which in turn will reduce feeding rate (Blaxter 1974). Constraints associated with depth are also linked to buoyancy control. If the distance between the bottom and the pelagic layers of food is too great, the additional energy cost associated with hydrodynamic lift production can limit the ability of cod to stay in deeper areas. The energetic considerations of buoyancy control (Strand et al. 2005) and the limits that this imposes on the vertical movements (Arnold \& Greer-Walker 1992, Godø \& Michalsen 2000, van der Kooij et al. 2007) make it more beneficial for cod not to enter the deepest areas of the BS.

We demonstrated constraints on the spatial distribution of cod in relation to polar cod. Cod fed efficiently on polar cod where they overlapped, but cod abundance was low in the northeastern parts dominated by polar cod. However, Russian studies indicate that in warm years cod might reach the maximum extent of their distribution later in the year (Yaragina et al. 2003). Therefore, our data may represent actively moving cod that are penetrating farther into the northern BS, and the negative overlap we found between cod and polar cod might therefore not hold later on in the season.

The cost of movement from the spawning areas in Lofoten and over-wintering areas in the southern BS may constrain the access of cod to the northeastern parts of the BS inhabited by polar cod. An observed spatial shift in the spawning area of cod as a response to climate change (Sundby \& Nakken 2008) has indicated that there may be a maximum feasible distance for the annual migrations from the feeding areas to the spawning areas. Also, reconstructions of cod migrations in the BS have revealed that in order to travel the distances involved, the cod would have required the assistance of north-flowing currents in addition to maintaining close to their maximum sustainable swimming speed (Ådlandsvik et al. 2007). These results indicate that there might be a considerable cost in terms of time and energy spent migrating.

The northeastern BS is covered by ice in winter and is generally cold $\left(<0^{\circ} \mathrm{C}\right)$. However, in the study years, the BS was unusually warm, especially in its northern parts, and bottom temperatures above $0^{\circ} \mathrm{C}$ were 
recorded in most of the northern BS (Levitus et al. 2009, Lind \& Ingvaldsen 2012). Indeed, during the study period most of the BS had bottom temperatures between 0 and $3^{\circ} \mathrm{C}$ (Johannesen et al. 2012), including the distribution area of polar cod and capelin. Tagging studies have shown that BS cod may sustain temperatures of around $0^{\circ} \mathrm{C}$ for long periods (Godø \& Michalsen 2000, Righton et al. 2010). E. Johannesen (unpublished) failed to find a clear relationship between cod distribution and temperature using the present data. Still, our study demonstrates that cod changed their distribution according to changes in local temperature; when the initial temperature was high, cod responded (slightly) negatively to a further increase in temperature, and conversely, when the temperature was initially low, cod responded positively to a rise in temperature. Therefore, we cannot firmly conclude whether temperature is imposing the spatial constraint on cod relative to polar cod under current conditions. The spatial anchor constraining polar cod and cod overlap at this time of year might be related to temperature and/or migration costs.

\section{Limitations of the study}

Our data are probably among the best large-scale datasets on cod and prey interactions in existence, as they cover the whole distribution range of the largest cod stock in the world. We are not considering the well known seasonal variation in BS cod feeding (e.g. Orlova et al. 2005, Michalsen et al. 2008). Therefore, our results do not hold for other times of the year.

Due to lack of reliable data on local abundance of krill, we could not study the spatial interaction of cod and this important prey (constituting $\sim 10 \%$ of the individual consumption in our study). The pelagic trawl that was not suitable for sampling krill (partly due to large diurnal migrations), was probably also sub-optimal for amphipod sampling, since it is constructed to sample 0-group fish. This might have contributed to the weak responses we found to amphipods.

We pooled cod over a large size range, and thus our data consist of cod that are heterogeneous with respect to maximum swimming speed and gap width. We restricted number of prey considered to 5 different groups. Together, this might have contributed to the relatively low proportion of variation explained by our analyses. On average, our 5 focal prey groups constituted $\sim 35 \%$ of individual consumption. The remaining $65 \%$ consisted of $\sim 20 \%$ that was too digested for meaningful classification (indetermina- tus, unclassified fish or crustaceans) and $10 \%$ krill. The remaining $35 \%$ comprised $>50$ other prey or prey groups, none of which had a high importance as cod prey (Supplement 1). However, by focusing only on 5 prey groups, we could justify ignoring the effect of cod size. Cod can feed on fish that are more than half of their size (e.g. Scharf et al. 2000), and our focal species were quite small (during our survey, most capelin were between 10 and $14 \mathrm{~cm}$, polar cod were between 10 and $14 \mathrm{~cm}$, and juvenile herring were between 10 and $20 \mathrm{~cm}$ ). Furthermore, initial analyses showed that the relationships between cod and the prey that we studied here were similar across different length groups for cod $\geq 30 \mathrm{~cm}$.

Scale is an important determinant of predator-prey interactions, but our study was not scale explicit. We used the inter-station distance to determine the size of our grid cells and the resolution of our study. Our underlying data were sampled at different scales and with different gear. The pelagic and bottom trawls from the same ecosystem station were usually taken within $\sim 2 \mathrm{~h}$ and distance from start to end of $\sim 4 \mathrm{n}$ miles $(\sim 7.5 \mathrm{~km})$, but were separated vertically, and sometimes the distance in space and time was greater due to e.g. other sampling activities and technical difficulties e.g. imposed by bottom topography. In some areas (mainly in the deepest areas) and years, the distance between bottom trawl stations was smaller (Wieneroither et al. 2011), and here we averaged stations by grid cell. The resolution of the hydro-acoustic data is finer (1 or $5 \mathrm{n}$ miles), but we used distance-weighted averages around the bottom trawl stations. The stomach data were taken from bottom trawl station catches, but cod might have fed at some unknown distance from the trawl station. Due to the slow digestion in cold water, cod might even have eaten outside the $35 \times 35 \mathrm{n}$ mile grid cell where they was caught, although we deem this to be unlikely. Consequently, our observations are determined by several processes operating at several undefined scales that are difficult to study directly. Further, there was spatial auto-correlation $>35 \mathrm{n}$ miles (the resolution of our study) that we did not account for, and therefore our $\mathrm{p}$ values and confidence intervals might be too small (Legendre et al. 2002), but this should not lead to bias in the estimates of the effects.

\section{Implications for the BS food web}

Active feeding migrations of cod under the warm conditions that characterized the years of study made 
the food resources of the northern BS available, and this may have buffered the impact of the recent capelin stock collapse. The cod stock used a large area, whereas prey were found in more segregated niches (Skern-Mauritzen et al. 2011). Cod had seemingly unconstrained access to capelin and were also able to feed successfully at the border of the distribution of the abundant polar cod (during the years of study there were on average $83.5 \times 10^{9}$ ind. polar cod, range: 44.1-132.9 × 109 ${ }^{9}$ IMR/PIMRO 2010). Constraints on cod in relation to shrimp (determined by depth) and polar cod and amphipods (determined by temperature and/or migration distance) should stabilize these predator-prey interactions, whereas the lack of constraint of cod relative to capelin should be destabilizing. However, to integrate the results on the interaction between cod and the different prey and to infer the consequences for the BS food web dynamics is complex, in particular since cod are omnivorous. Omnivory might produce simultaneous conflicting direct and indirect effects on the same species or trophic level (Agrawal 2003, Bascompte et al. 2005). In the BS, indirect interactions may be as important as or more important than direct interactions (e.g. Bogstad et al. 1997, Lindstrøm et al. 2009). For example, by running modelling experiments, Lindstrøm et al. (2009) showed that increased predation by minke whales Balaenoptera acutorostrata benefit capelin, even though capelin are taken by whales, because whales also prey on the cod stock.

In the future, empirical studies should consider seasonal aspects of cod feeding and constraints on cod-prey interactions. These studies should be integrated with models including indirect and direct predation effects to test for the importance of spatial constraints on food web dynamics under different oceanographic regimes.

Acknowledgements. We thank all who participated in the ecosystem surveys, in particular the staff who analysed the cod stomach contents. G. O. Johansen is thanked for valuable discussions and comments on the manuscript. K. Gjertsen made Fig. 1. The Norwegian Research Council funded the work by E.J., M.S.M., U.L. and P.F. on the project BarSpat (NRC contract no. 173348/S40) and the work by E.J., M.S.M. and K.M. on the project BarEcoRe (NRC contract no. 200793/S30). We thank H. Allen for correction of the English.

\section{LITERATURE CITED}

Ådlandsvik B, Huse G, Michalsen K (2007) Introducing a method for extracting horizontal migration patterns from data storage tags. Hydrobiologia 582:187-197

Agrawal AA (2003) Why omnivory? Ecology 84:2521
Ajiad A, Oganin IA, Gjøsæter H (2011) Polar cod. In: Jakobsen T, Ozhigin VK (eds) The Barents Sea ecosystem, resources, management. Half a century of Russian-Norwegian cooperation. Tapir Academic Press, Trondheim, p 315-328

Alonzo SH, Switzer PV, Mangel M (2003) Ecological games in space and time: the distribution and abundance of Antarctic krill and penguins. Ecology 84:1598-1607

Armstrong JB, Schindler DE (2011) Excess digestive capacity in predators reflects a life of feast and famine. Nature 476:84-87

Arnold GP, Greer-Walker M (1992) Vertical movements of cod (Gadus morhua L) in the open sea and the hydrostatic function of the swimbladder. ICES J Mar Sci 49: 357-372

Bascompte J, Melian CJ, Sala E (2005) Interaction strength combinations and the overfishing of a marine food web. Proc Natl Acad Sci USA 102:5443-5447

Berenboim BI, Dolgov AV, Korzhev VA, Yaragina NA (2000) The impact of cod on the dynamics of the Barents Sea shrimp (Pandalus borealis) as determined by multispecies models. J Northwest Atl Fish Sci 27:69-75

Blaxter JHS (1974) The role of light in the vertical migration of fish - a review. In: Evans GC, Bainbridge $\mathrm{R}$, Rackham O (eds) Light as an ecological factor II: 16th Symp Brit Ecol Soc. Blackwell Scientific Publications, Oxford, p 189-210

Bogstad B, Mehl S (1997) Interactions between Atlantic cod (Gadus morhua) and its prey species in the Barents Sea. In: Proceedings of the International Symposium on the Role of Forage Fishes in Marine Ecosystems. Alaska Sea Grant College Program Report No 97-01. University of Alaska, Fairbanks, AK, p 591-615

Bogstad B, Pennington M, Vølstad JH (1995) Cost-efficient survey designs for estimating food consumption by fish. Fish Res 23:37-46

$>$ Bogstad B, Hauge KH, Ulltang $\varnothing$ (1997) MULTSPEC - a multispecies model for fish and marine mammals in the Barents Sea. J Northwest Atl Fish Sci 22:317-341

> Ciannelli L, Bailey KM (2005) Landscape dynamics and resulting species interactions: the cod-capelin system in the southeastern Bering Sea. Mar Ecol Prog Ser 291: 227-236

Cohen DM, Inada T, Iwamoto T, Scialabba N (1990) FAO species catalogue Vol 10. Gadiform fishes of the world (Order Gadiformes). An annotated and illustrated catalogue of cods, hakes, grenadiers and other gadiform fishes known to date. FAO Fish Synop 10: 1-442

> Corfield J (2000) The effects of acid sulphate run-off on a subtidal estuarine macrobenthic community in the Richmond River, NSW, Australia. ICES J Mar Sci 57: 1517-1523

Dalpadado P, Bogstad B (2004) Diet of juvenile cod (age 0-2) in the Barents Sea in relation to food availability and cod growth. Polar Biol 27:140-154

> Dalpadado P, Borkner N, Bogstad B, Mehl S (2001) Distribution of Themisto (Amphipoda) spp. in the Barents Sea and predator-prey interactions. ICES J Mar Sci 58: 876-895

> Dalpadado P, Bogstad B, Eriksen E, Rey L (2009) Distribution and diet of 0-group cod (Gadus morhua) and haddock (Melanogrammus aeglefinus) in the Barents Sea in relation to food availability and temperature. Polar Biol 32: 1583-1596 
Dos Santos J, Jobling M (1992) A model to describe gastric evacuation in cod (Gadus morhua L.) for natural prey. ICES J Mar Sci 49:145-154

Eriksen E, Dalpadado P (2011) Long-term changes in krill biomass and distribution in the Barents Sea: Are the changes mainly related to capelin stock size and temperature conditions? Polar Biol 34:1399-1409

> Eriksen E, Prozorkevich DV, Dingsør GE (2009) An evaluation of 0-group abundance indices of the Barents Sea fish stocks. Open Fish Sci J 2:6-14

Fauchald P (2009) Spatial interaction between seabirds and prey: review and synthesis. Mar Ecol Prog Ser 391: 139-151

Fauchald P, Mauritzen M, Gjøsæter H (2006) Densitydependent migratory waves in the marine pelagic ecosystem. Ecology 87:2915-2924

Frank KT, Petrie B, Choi JS, Leggett WC (2005) Trophic cascades in a formerly cod-dominated ecosystem. Science 308:1621-1623

> Fretwell SD, Lucas HL (1969) On territorial behavior and other factors influencing habitat distribution in birds. Acta Biotheor 19:16-36

Gjøsæter H, Dommasnes A, Røttingen B (1998) The Barents Sea capelin stock 1972-1997. A synthesis of results from acoustic surveys. Sarsia 83:497-510

Gjøsæter H, Bogstad B, Tjelmeland S (2009) Ecosystem effects of three capelin stock collapses in the Barents Sea. In: Haug T, Røttingen I, Gjøsæter H, Misund, OA (eds) Fifty years of Norwegian-Russian collaboration in marine research. Thematic issue No 2. Mar Biol Res 5: 40-53

Godø OR, Michalsen K (2000) Migratory behaviour of northeast Arctic cod, studied by use of data-storage tags. Fish Res 48:127-140

Hallfredsson EH, Pedersen T (2009) Effects of predation from juvenile herring (Clupea harengus) on mortality rates of capelin (Mallotus villosus) larvae. Can J Fish Aquat Sci 66:1693-1706

Harden Jones FR (1968) Fish migration. Arnold, London

> Horne JK, Schneider DC (1994) Lack of spatial coherence of predators with prey-a bioenergetic explanation for Atlantic cod feeding on capelin. J Fish Biol 45:191-207

Hvingel C (2006) Towards a quantitative assessment framework for the shrimp (Pandalus borealis) stock in the Barents Sea. NAFO SCR Doc. 06/64. Northwest Atlantic Fisheries Organization, Dartmouth, NS

Hylen A, Nakken O, Nedreaas K (2008) Northeast Arctic cod: fisheries, life history, stock fluctuations and management. In: Nakken O (ed) Norwegian spring-spawning herring and Northeast Arctic cod. Tapir Academic Press, Trondheim, p 83-118

ICES (International Council for the Exploration of the Sea) (2011) Report of the Arctic Fisheries Working Group, Hamburg, 28 April-4 May 2011. ICES CM 2011/ACOM: 05. ICES, Copenhagen

IMR/PINRO (Institute of Marine Research/Polar Research Institute of Marine Fisheries and Oceanography)(2010) Survey report from the joint Norwegian/Russian ecosystem survey in the Barents Sea August-September 2010. IMR/PINRO Joint Report Series, No 4/2010. IMR/PINRO, Bergen, Tromsø, Murmansk

Johannesen E, Ingvaldsen RB, Bogstad B, Dalpadado P and others (2012) Changes in Barents Sea ecosystem state 1970-2009: climate fluctuations, human impact and trophic interactions. ICES J Mar Sci 69:880-889
Johansen GO (2003) Size-dependent predation on juvenile herring (Clupea harengus L.) by North-east Arctic cod (Gadus morhua L.) in the Barents Sea. Sarsia 88: 136-153

> Jørgensen T (1992) Long-term changes in growth of northeast Arctic cod (Gadus morhua) and some environmental influences. ICES J Mar Sci 49:263-277

Kjesbu OS, Witthames PR, Solemdal P, Walker MG (1998) Temporal variations in the fecundity of Arcto-Norwegian cod (Gadus morhua) in response to natural changes in food and temperature. J Sea Res 40:303-321

> Legendre P, Anderson MJ (1999) Distance-based redundancy analysis: testing multispecies responses in multifactorial ecological experiments. Ecol Monogr 69:1-24

Legendre P, Legendre L (1998) Numerical ecology, 2nd edn. Elsevier Science, Amsterdam

> Legendre P, Dale MRT, Fortin MJ, Gurevich J, Holm M, Myers D (2002) The consequences of spatial structure of the design and analysis of ecological field surveys. Ecography 25:601-615

Levitus S, Matisov G, Seidov D, Smolyar I (2009) Barents Sea multidecadal variability. Geophys Res Lett 36:L19604 doi:10.1029/2009GL039847

Lind S, Ingvaldsen RB (2012) Variability and impacts of Atlantic water entering the Barents Sea from the north. Deep-Sea Res I 62:70-88

Lindstrøm U, Smout S, Howell D, Bogstad B (2009) Modelling multispecies interactions in the Barents Sea ecosystem with special emphasis on minke whales, cod, herring and capelin. Deep-Sea Res II 56:2068-2079

Link JS, Garrison LP (2002) Trophic ecology of Atlantic cod Gadus morhua on the northeast US continental shelf. Mar Ecol Prog Ser 227:109-123

Link JS, Bogstad B, Sparholt H, Lilly GR (2009) Role of cod in the ecosystem. Fish Fish 10:58-87

Mehl S (1991) The northeast Arctic cod stocks place in the Barents Sea ecosystem in the 1980s - an overview. Polar Res 10:525-534

Mehl S, Yaragina NA (1992) Methods and results in the joint PINRO-IMR stomach sampling program. In: Bogstad B, Tjelmeland $\mathrm{S}$ (eds) Interrelations between fish populations in the Barents Sea. Proc 5th PINRO-IMR Symp, 12-16 August 1991, Murmansk. Institute of Marine Research, Bergen, p 5-16

> Michalsen K, Johannesen E, Bogstad B (2008) Feeding of mature cod (Gadus morhua) on the spawning grounds in Lofoten. ICES J Mar Sci 65:571-580

Michalsen K, Dalpadado P, Eriksen E, Gjøsæter H and others (2011) Proc 15th Norwegian-Russian Symp Svalbard 'Climate change and effects on the Barents Sea marine living resources', 7-8 September August 2011. IMR/ PINRO Joint Report Ser. IMR/PINRO, Bergen, Tromsø, Murmansk, p 247-272

Nakken O (1998) Past, present and future exploitation and management of marine resources in the Barents Sea and adjacent areas. Fish Res 37:23-35

Orlova EL, Dolgov AV, Seliverstova EI (1995) Character of cod effect on population of herring in the Barents Sea. In: Hylen A (ed) Precision and relevance of pre-recruit studies for fishery management related to fish stocks in the Barents Sea and adjacent waters. Proc 6th IMR-PINRO Symp, Bergen, 14-17 June 1994. Institute of Marine Research, Bergen, p 85-106

Orlova EL, Dolgov AV, Rudneva GB, Nesterova VN (2005) The effect of abiotic and biotic factors on the importance 
of macroplankton in the diet of Northeast Arctic cod in recent years. ICES J Mar Sci 62:1463-1474

Orlova EL, Dolgov AV, Rudneva GB, Oganin IA, Konstantinova LL (2009) Trophic relations of capelin Mallotus villosus and polar cod Boreogadus saida in the Barents Sea as a factor of impact on the ecosystem. Deep-Sea Res II 56:2054-2067

Pinheiro JC, Bates DM, DebRoy S, Deepayan S (2006) nlme: linear and nonlinear mixed effects model $R$ package version 31-77. Available at www.R-project.org

Righton DA, Andersen KH, Neat F, Thorsteinsson V and others (2010) Thermal niche of Atlantic cod Gadus morhua: limits, tolerance and optima. Mar Ecol Prog Ser 420:1-13

Rose GA, Leggett WC (1990) The importance of scale to predator-prey spatial correlations: an example of Atlantic fishes. Ecology 71:33-43

Sandeman LR, Yaragina NA, Marshall CT (2008) Factors contributing to inter- and intra-annual variation in condition of cod Gadus morhua in the Barents Sea. J Anim Ecol 77:725-734

Scharf FS, Juanes F, Rountree RA (2000) Predator size-prey size relationships of marine fish predators: interspecific variation and effects of ontogeny and body size on trophic-niche breadth. Mar Ecol Prog Ser 208:229-248

Sih A (2005) Predator-prey space use as an emergent outcome of a behavioural response race. In: Barvosa P, Castelannos I (eds) Ecology of predator-prey interactions. Oxford University Press, New York, NY, p 240-255

Skern-Mauritzen M, Johannesen E, Bjørge A, Øien N (2011) Baleen whale distributions and prey associations in the Barents Sea. Mar Ecol Prog Ser 426:289-301

Strand E, Jørgensen C, Huse G (2005) Modelling buoyancy regulation in fishes with swimbladders: bioenergetics and behavior. Ecol Model 185:309-327

Sundby S, Nakken O (2008) Spatial shifts in spawning habitats of Arcto-Norwegian cod related to multidecadal climate oscillations and climate change. ICES J Mar Sci 65: 953-962

Temming A, Herrmann JP (2003) Gastric evacuation in cod: prey-specific evacuation rates for use in North Sea, Baltic

Editorial responsibility: Nicholas Tolimieri, Seattle, Washington, USA
Sea and Barents Sea multi-species models. Fish Res 63: 21-41

van der Kooij J, Righton D, Strand E, Michalsen K and others (2007) Life under pressure: insights from electronic datastorage tags into cod swimbladder function. ICES J Mar Sci 64:1293-1301

> van Leeuwen A, De Roos AM, Persson L (2008) How cod shapes its world. J Sea Res 60:89-104

Wienerroither R, Johannesen E, Dolgov A, Byrkjedal I and others (eds) (2011) Atlas of the Barents Sea fishes. IMR/ PINRO Joint Report Series No. 1/2011. www.imr.no/ filarkiv/2011/09/atlas_august_2011_press_quality_til_web .pdf/en

Wood SN (2006) Generalized additive models: an introduction with R. Chapman \& Hall/CRC, Boca Raton, FL

Worm B, Myers RA (2003) Meta-analysis of cod-shrimp interactions reveals top-down control in oceanic foodwebs. Ecology 84:162-173

Yaragina NA, Marshall CT (2000) Trophic influences on interannual or seasonal variation in the liver condition index of Northeast Arctic cod (Gadus morhua). ICES J Mar Sci 57:42-55

Yaragina NA, Ponomarenko VP, Shevelev MS (2003) Migrations. In: Shleinik VN (ed) The Barents Sea cod: biology and fishery, 2nd edn. PINRO Press, Murmansk, p 30-50 (in Russian)

Yaragina NA, Aglen A, Sokolov KM (2011) Cod. In: Jakobsen T, Ozhigin VK (eds) The Barents Sea ecosystem, resources, management. Half a century of Russian-Norwegian cooperation. Tapir Academic Press, Trondheim, p 225-270

Zatsepin VJ, Petrova NS (1939) Feeding of cod in the south part of the Barents Sea (by observations in 1934-1938). Trudy PINRO 5:1-170 (in Russian)

> Zhukova NG, Nesterova VN, Prokopchuk IP, Rudneva GB (2009) Winter distributions of euphausiids (Euphausiacea) in the Barents Sea (2000-2005). Deep-Sea Res II 56:1959-1967

Zuur A, Ieno E, Walker N, Saveliev A, Smith G (2009) Mixed effects models and extensions in ecology with $\mathrm{R}$. Springer, New York, NY

Submitted: December 19, 2011; Accepted: May 11, 2012 Proofs received from author(s): June 20, 2012 